\title{
Strength anisotropy at soil-structure interfaces with snake skin inspired structural surfaces
}

\author{
Hans Henning Stutz ${ }^{1,}$, Alejandro Martinez ${ }^{2}$, Lars Heepe ${ }^{3}$, Halvor Tram Tramsen ${ }^{3}$, and Stanislav N. Gorb ${ }^{3}$ \\ ${ }^{1}$ Aarhus Universitet, Department of Engineering, Inge Lehmanns Gade 10, 8000 Aarhus C, Denmark \\ ${ }^{2}$ University of California Davis, Department of Civil and Environmental Engineering, 2001 Ghausi, Davis, CA, USA \\ ${ }^{3}$ University of Kiel, Department of Functional Morphology and Biomechanics, Zoological Institute, Am Botanischen Garten 1-9, 24098 \\ Kiel, Germany
}

\begin{abstract}
Typical soil-structure interfaces exhibit a response that is independent of loading direction due to the symmetry of the surfaces' profile. This study presents results from an experimental investigation on the response of sand specimens sheared against three types of surfaces bio-inspired from the skin along the underside of snakes. The results of shear box interface shear tests indicate that all three surfaces exhibit significant anisotropy in response in terms of mobilized shear resistances and corresponding volumetric changes. A discussion on the practical implications and potential benefits of implementation of the snake skin-inspired surfaces in engineering design is provided.
\end{abstract}

\section{Introduction}

The behaviour of sand-structure interfaces is a subject of ongoing research considering their importance for the design and capacity of many geotechnical structures, such as retaining walls, deep foundations, tunnel-linings, and shallow foundations subjected to inclined loads. Beside the influences of factors such as soil density, particle shape, normal stress, and test conditions $[1,2,3,4,5,6$, $7,8]$, the influence of the surface roughness magnitude and form is of great importance $[9,10,11]$.

Usually, the strength of a soil-structure interface is a function of the surface's roughness and hardness $[3,4,6]$. In addition, other authors such as Irsyam and Hryciw [12] studied the effect of topology and geometrical arrangement of the surface profile for a series of ribbed surfaces. Martinez and Frost [11] showed that surfaces with diamond shaped asperities mobilize interface friction as well as passive resistances which lead to conditions $\delta>\varphi$ (interface friction angles large then soil friction angles). Similar results were reported by [12].

Beside the classical ways of describing surface profile and surface roughness, a novel approach combining bioinspiration and additive manufacturing was used by Martinez and Palumbo [13]. The authors showed that surfaces bio-inspired from the geometry of snake skin mobilized different shear strengths depending on whether the bio-inspired surface was displaced in the "along the scales" (i.e. forward) and "against the scales" (i.e. backward) direction relative to the soil. The authors referred to this behaviour as "frictional anisotropy", which is controlled by the interactions between the surface asperities and the soil particles. Thus, this frictional anisotropy is different from the inherent fabric soil anisotropy reported for interface shearing by authors such as Farhadi and Lashkari [14].

Friction anisotropy is present in many biological surfaces that have an asymmetric arrangement of surface nano- and micro-structural features [15]. Examples range from the hairy adhesive pads on some geckos, spiders, and insects [16, 17], scale-like arrangement and microornamentation of snakeskin $[18,19,20,21]$, denticlecovered shark skin [22], plant surfaces with cuticular folds and wax coverage [23], and silicified hairs on wheat awns [24]. Such anisotropies in biological surfaces usually serve the generation of motion in a preferred direction, either for the purpose of locomotion or for the transportation of fluids and particles [15]. Moreover, it was recently shown that friction anisotropy is not solely controlled by an asymmetric surface topography itself, but also strongly influenced by the effective stiffness (bending) of the actual surface structures [25].

The aim of the research presented herein is to study the effect of asymmetric surface asperities on the soilstructure interface behaviour of sand specimens. An additional aim of this research is to identify possible mechanisms that lead to an increase in shear strength in snakeskin-inspired surfaces. The results from direct interface shear tests performed on specimens of two different sands are presented. Discussion is provided regarding two different approaches to quantify the mobilized frictional anisotropy as well as regarding the practical implications and potential benefits of implementation of the bio-inspired surfaces in geotechnical engineering design.

\footnotetext{
* Corresponding author: hhs@eng.au.dk
} 


\section{Test set-up and methodology}

\subsection{Shear box interface testing device and sand}

The OSInterface testing device was used in this study [26]. This modified direct shear device is adapted for shear box-type soil-structure interface shear testing. The specimen size is of $100.0 \mathrm{~mm}$ in length, $64.0 \mathrm{~mm}$ in width, and $32.5 \mathrm{~mm}$ in height. All the tests were performed using constant normal load boundary conditions for control of the normal stress $\left(\sigma_{\mathrm{n}}\right)$ applied to the sand specimens. The normal and shear forces and displacements were measured using $5 \mathrm{kN}$ load cells and linear potentiometers. All tests were performed at a normal vertical stress of $75 \mathrm{kPa}$, and the specimens were sheared at a rate of horizontal displacement of $1 \mathrm{~mm} / \mathrm{min}$ in consistency with previous studies $[2,13]$. All tests consisted of one twoway cycle with a displacement amplitude of $10.5 \mathrm{~mm}$. The specimens were sheared either in the backwards (i.e. "against the scales) or forwards (i.e. "along the scales") direction in the first half-cycle (as shown Figure 1). This means that the specimens were sheared in the opposite direction on the second half-cycle of the test. Specimens of Hostun sand $\left(\mathrm{D}_{50}=0.33 \mathrm{~mm}\right.$, angular particle shape) and Ottawa F-65 sand $\left(\mathrm{D}_{50}=0.20 \mathrm{~mm}\right.$, sub-rounded particle shape) prepared to a relative density of $80 \%$ were tested in this study. Testing both sands allowed study of the effect of particle angularity on the mobilization of frictional anisotropy.

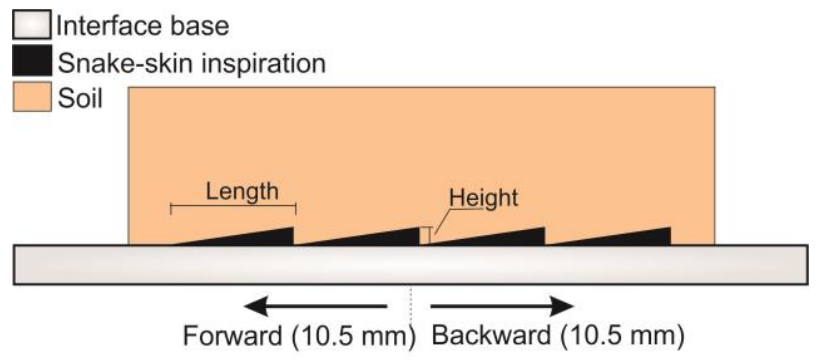

Fig. 1. Interface shear specimen configuration

\subsection{Structural surfaces}

The structural surfaces were generated through additive manufacturing using the Formlabs Form2 3D printer which uses the stereolithography technique. The surfaces were printed using a layer thickness of $25 \mu \mathrm{m}$. The general shape of the profile configuration of the surfaces is shown in Figure 1, with an asperity height $(\mathrm{H})$ of $0.5 \mathrm{~mm}$ and asperity length (L) that ranged from 21 to $60 \mathrm{~mm}$. The surfaces had areas with bio-inspired texturing that were $80 \mathrm{~mm}$ in length, and untextured areas with a length of 10 $\mathrm{mm}$ at both ends to reduce boundary effects, in consistency with other studies [2, 13, 27]. The surfaces were mounted on the testing platform to perform tests that either started in the "backward" direction in the first halfcycle, or in the "forward" direction in the first half-cycle, as indicated in Figure 1. This resulted in a testing sequence that consisted in backward shearing during the first half-cycle and forward shearing in the second half- cycle, and vice versa. Additional tests were performed on surfaces consisting of sand glued on steel and 3D printed untextured profiles that provided baseline response for "fully rough" and "smooth" interfaces, respectively. Tests with the glued sand surface provided the response of an interface where the main failure mechanism is internal soil deformation, while tests with the untextured surface provided a response characterized by sliding between the sand particles and the contacting surface.

\section{Stress deformation behaviour}

In the following sections, the stress-deformation characteristics of soil-structure interfaces composed of snake skin-inspired surfaces and angular (Hostun) and rounded (Ottawa F-65) sand are presented.

\subsection{Hostun Sand}

The shear stress mobilized during the tests performed in the forward direction first was relatively similar to that mobilized by the untextured "smooth" surface, as shown in Figure $2 \mathrm{a}$ for the $\mathrm{L}=21 \mathrm{~mm}$ surfaces. On the other hand, shearing in the backward direction first mobilized shear stresses that were close in magnitude to those mobilized by the fully rough "glued sand" surface. These results highlight that the frictional anisotropy mobilized by the snake-skin inspired surfaces. As the scale length was increased, the mobilized shear resistances in the forward and backward directions decreased, most likely due to the decreased interactions between the asperities along the surfaces as shown in Figures $2 \mathrm{c}$ and $2 \mathrm{e}$ for the $\mathrm{L}=41$ and $60 \mathrm{~mm}$ surfaces. The mobilized peak and residual shear stresses are summarized in Figures $4 \mathrm{a}$ and $4 \mathrm{~b}$ as a function of asperity length.

The volumetric change results shown in Figure $2 b$ indicate that the test performed in the backward direction first induced a larger dilation magnitude than that performed in the forward direction first. In addition, the volume change response mobilized during the backward direction was similar to that exhibited by the test against the glued sand surface. The dilative response became less pronounced as the asperity length was increased, as shown in Figures $2 \mathrm{~d}$ and $2 \mathrm{f}$ for the $\mathrm{L}=41$ and $60 \mathrm{~mm}$ surfaces. It should be noted that an increasing asperity length also influences the number of scales on a given surface due to the constant textured length of $80 \mathrm{~mm}$. 

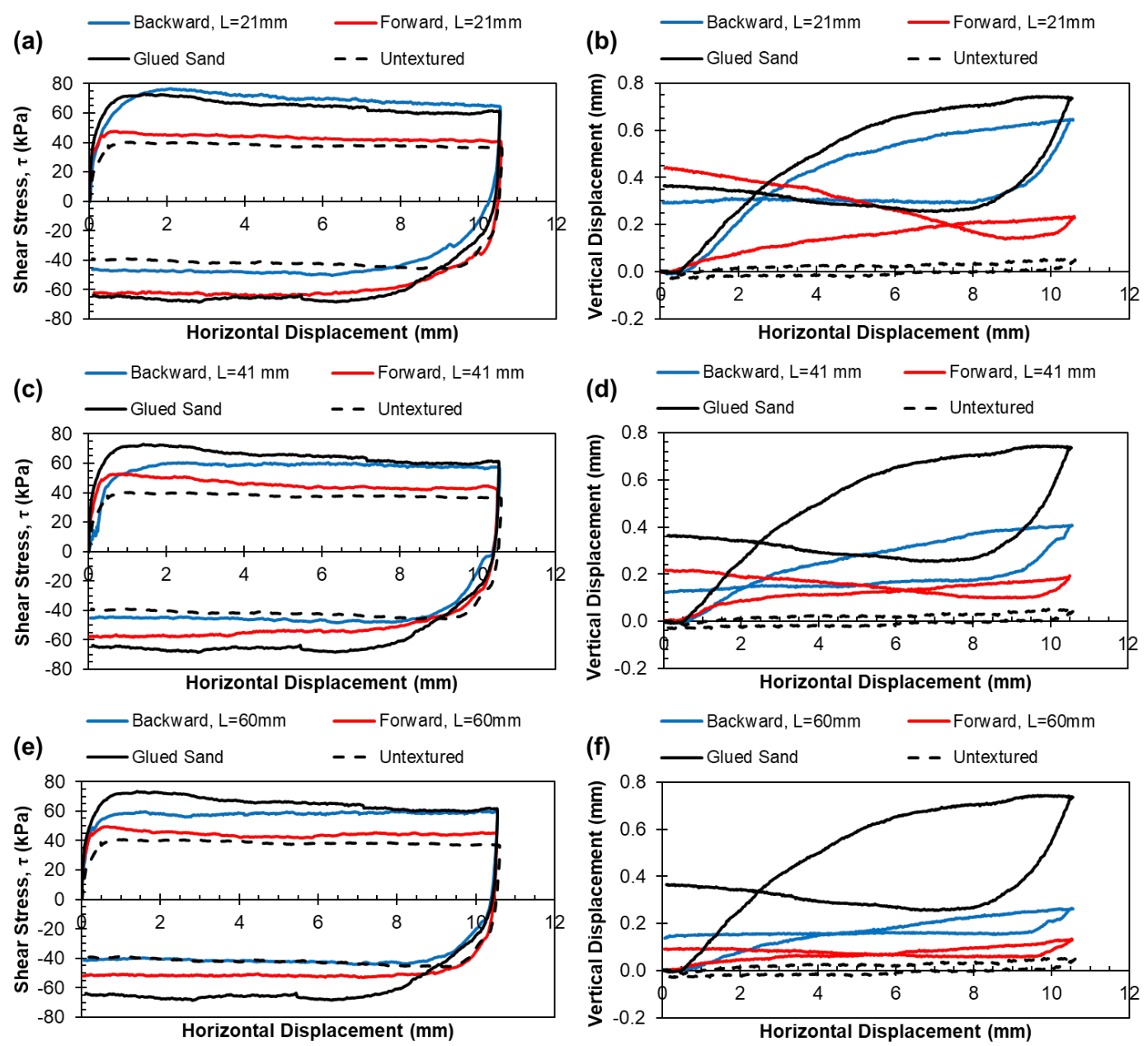

Fig. 2. Mobilized shear stresses and associated vertical displacements from tests on Hostun sand.

The mobilized shear stresses in the second half-cycle (negative shear stresses in Figures 2a, 2c and 2e, consisting of shearing in the opposite direction as that during the first cycle specified in the figure legends) follow a similar trend as that described above, where shearing in the backward direction mobilized larger shear stresses than shearing in the forward direction. This trend is consistent for all three surfaces, and indicates that frictional anisotropy is also mobilized within the first and second half-cycles of a given test (e.g. first half-cycle in the backward direction and second half-cycle in the forward direction). These results are summarized in Figure 4c.

\subsection{Ottawa F-65 Sand}

The results from tests on Ottawa F-65 sand exhibit similar trends as those described for the tests on Hostun sand. In general, shearing in the backward direction mobilized greater shear stresses, whether in the first half-cycle or the second half-cycle. The response of the backward first test with an asperity length of $21 \mathrm{~mm}$ was similar to that corresponding to the test against the glued sand surface, in terms of both mobilized shear stresses and volumetric changes (Figures $3 a$ and $3 b$ ). In the forward direction first, the induced volumetric changes were significantly smaller than those induced during the backward direction, highlighting that the bio-inspired surfaces also mobilized anisotropy in terms of soil dilation (Figure $3 \mathrm{~b}$ ). The mobilized shear stresses and induced volumetric changes decreased as the asperity length was increased to 41 and $60 \mathrm{~mm}$, as shown in Figures $3 \mathrm{c}$ through $3 \mathrm{e}$. The mobilized peak and residual values are summarized in Figures $4 \mathrm{a}$ through $4 \mathrm{c}$.

\section{Anisotropic interface soil-shear behaviour}

A definition of frictional anisotropy in terms of shear stresses was introduced by Martinez and Palumbo [13] to characterize the difference in mobilized shear resistances in a given test as:

$$
A_{1}=\left|\tau_{1}-\tau_{2}\right|
$$

where $\tau_{l}$ is the shear stress mobilized in the first halfcycle, and $\tau_{2}$ is the shear stress mobilized in the second half-cycle. In general, shearing in the backward direction, whether during the first of second half-cycle, mobilizes a larger shear stress. 

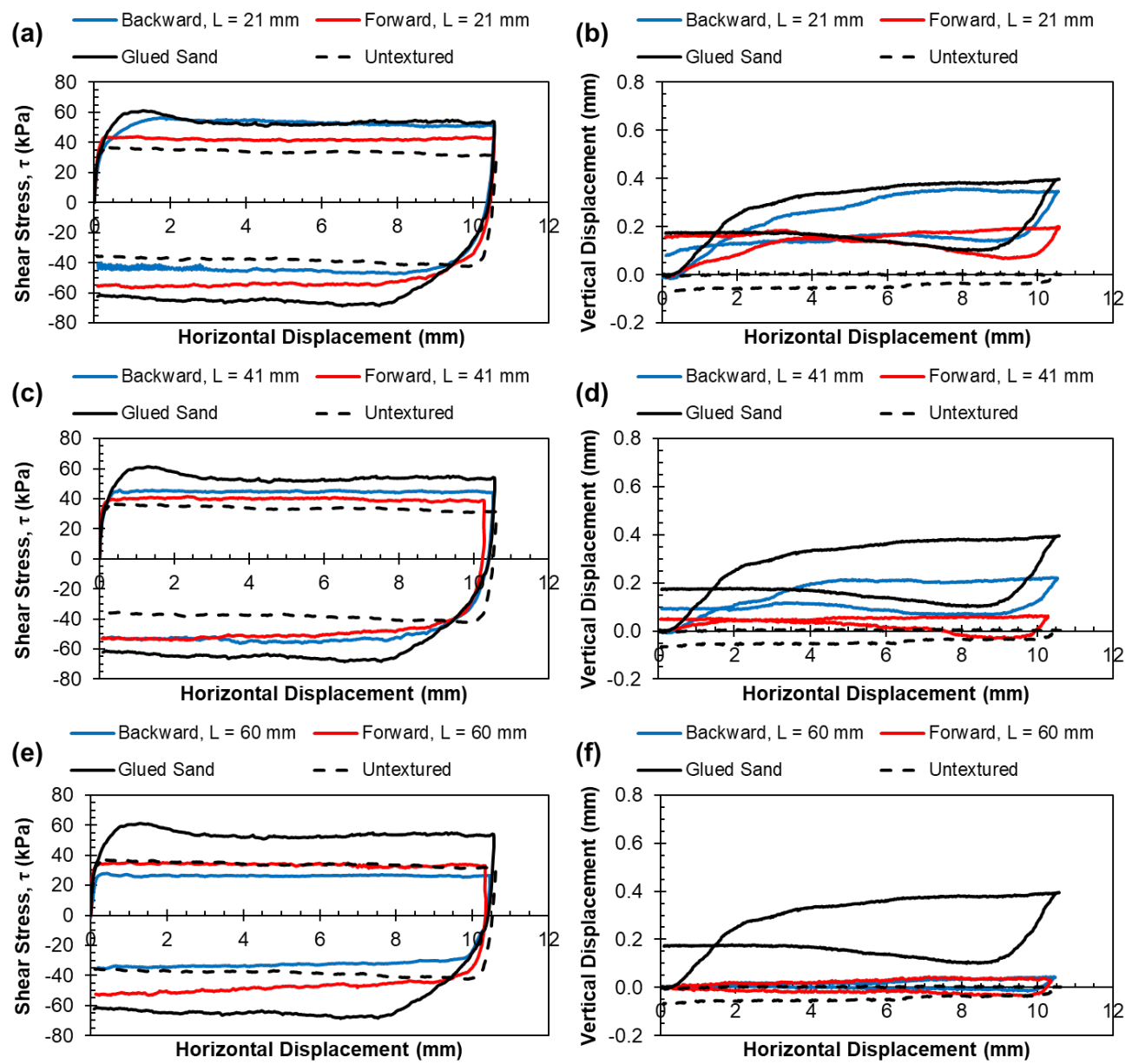

Fig. 3. Mobilized shear stresses and associated vertical displacements from tests on Ottawa F-65 sand.

Palumbo [28] introduced an alternate definition for frictional anisotropy, as follows:

$$
A_{2}=\left|\tau_{B}-\tau_{F}\right|
$$

where $\tau_{B}$ is the shear stress mobilized in the backward direction in the first half-cycle and $\tau_{F}$ is the shear stress mobilized in the forward direction in the first half-cycle. It should be noted that in this case $\tau_{B}$ and $\tau_{F}$ are obtained from different tests. In this manner, this parameter does not consider the effects of loading history on interface shear response. Both anisotropy parameters are used here to analyse the result from tests on Hostun and Ottawa F65 sand. As shown in Figure 5a, the frictional anisotropy mobilized in a given test can be as large as $30 \mathrm{kPa}$. This is significant considering that a vertical effective stress of 75 $\mathrm{kPa}$ was applied to all specimens. The $\mathrm{A}_{1}$ frictional anisotropy parameter generally decreases as the asperity length is increased; however, the specimens sheared in the backward first direction generally mobilized a larger anisotropy than those sheared in the forward direction first. The frictional anisotropy parameter $\mathrm{A}_{2}$ can also take values close to $30 \mathrm{kPa}$. However, the data does not yield a clear trend between the $\mathrm{A}_{2}$ parameter and asperity length. Further research is required to identify the parameters that influence the mobilized anisotropy. For instance, research is ongoing to address the effect of asperity height and sand relative density.

\section{Discussion and conclusions}

The results presented above highlight some interesting trends. In general, shearing in the backward direction mobilized larger shear stresses than shearing in the forward direction. This difference was observed when comparing the shear resistances from the first and second half-cycles in a given test, or the shear resistances mobilized in different tests. The mobilized frictional anisotropy was found to be quite large in certain situations. For instance, the ratio of shear stresses mobilized in the backward to forward direction for the tests with the $\mathrm{L}=21 \mathrm{~mm}$ surface is of 1.7 on Hostun sand and 1.4 on Ottawa F-65 sand.

The results indicate that frictional anisotropy is mobilized both in terms of the mobilized shear resistances as well as associated volumetric changes. This implies that soil dilation may play an important role in the difference in interface shear response. This observation is in agreement with the fact that tests on the more angular Hostun sand exhibited larger frictional anisotropy than the 

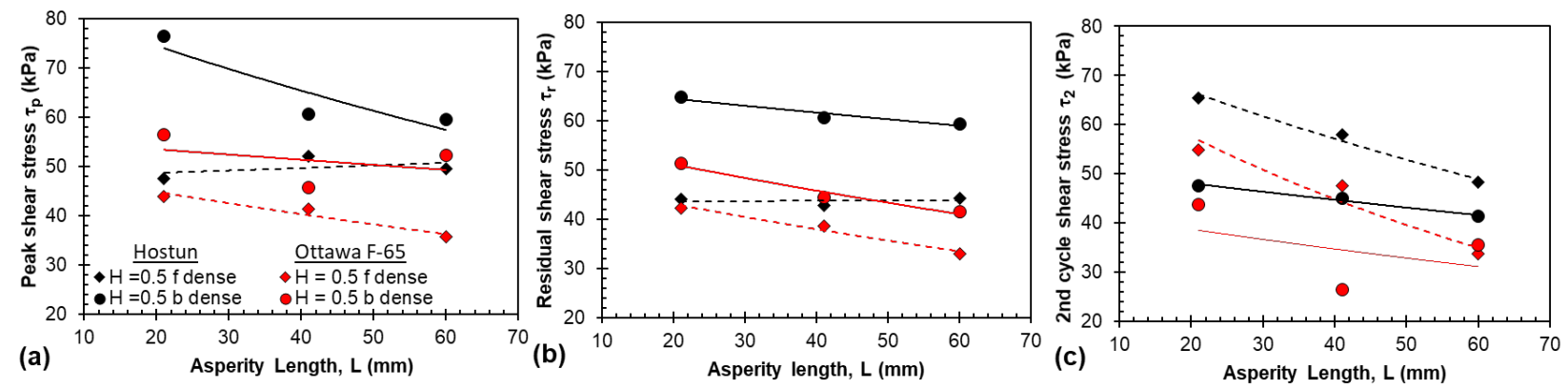

Fig. 4. Mobilized shear stresses: (a) Peak, (b) residual, and (c) $2^{\text {nd }}$ half-cycle.

tests performed on the sub-rounded Ottawa F-65. In addition, the results presented herein are in close agreement with trends from interface shear tests
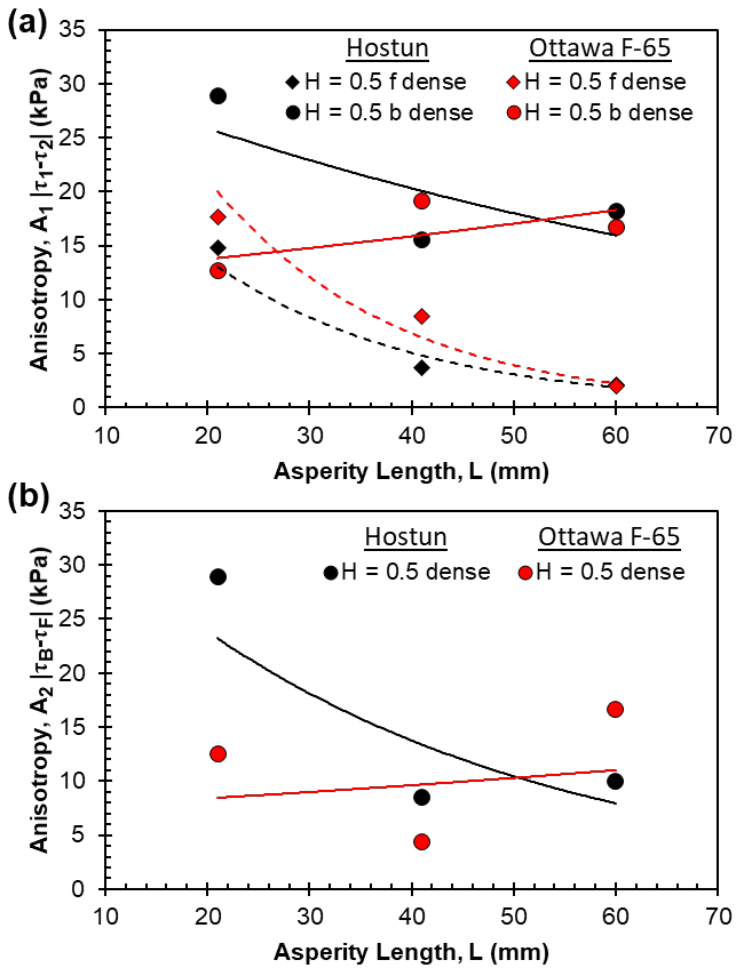

Fig. 5. (a) A1 and (b) A2 frictional anisotropy parameters from tests on Hostun and Ottawa F-65 sands.

performed on snake skin-inspired surfaces by Palumbo [28] and Martinez et al. [29]

These results presented in this paper imply that a significant frictional anisotropy could be achieved in the field if the surface of geotechnical structures are textured with the snake skin-inspired profiles studied herein. For instance, an offshore deep foundation would mobilize resistances during installation that would be 40 to $70 \%$ smaller than the capacity that could be mobilized during subsequent tensile loading. In a broader sense, bioinspiration may lead to development of efficient solutions in geotechnical engineering in areas such as deep and shallow foundations, earth retaining structures, site investigation, and tunnelling.
This material is based upon work supported in part by the National Science Foundation (NSF) under NSF CA No. EEC1449501. Any opinions, findings and conclusions or recommendations expressed in this material are those of the author(s) and do not necessarily reflect those of the NSF.

\section{References}

1. H. Kishida, M. Uesugi, Geotechnique, 37, 1, 45-52 (1987)

2. J. T. DeJong, Z. J. Westgate, J. of Geotech. Geoenv. Eng., 135, 11, 1646-1660 (2009)

3. F. Han, E. Ganju, R. Salgado, M. Prezzi, J. of Geotech. Geoenv. Eng., 144, 12 (2018).

4. J. Dove, J. Jarrett, J. of Geotech. Geoenv. Eng., 128(1), 25-37 (2002).

5. M. L. Lings, M. S. Dietz, Soils and Found., 45, 6, 114 (2005)

6. M. Samanta, P. Punetha, M. Sharma, Géotechnique Letters, 8, 1, 1-9 (2018)

7. V. Fioravante, V. N. Ghionna, S. Pedroni, D. A. Porcino, Rivista Italiana Di Geotecnica, 3, 7-22 (1999)

8. G. L. Hebeler, A. Martinez, J. D. Frost, KSCE J. of Civil Eng., 1-16 (2015)

9. A. Martinez, J. D. Frost, G.L. Hebeler, ASTM Geotech. Test. J., 38, 4, 409-426 (2015)

10. H. M. Abuel-Naga, H. A. Shaia, A. Bouazza, J. of Test. Ev., 46, 2, 826-831 (2018)

11. A. Martinez, J. D. Frost, Geotechnique Letters, 7, 1, 1-8 (2017)

12. M. Irsyam, R. D. Hryciw, Géotechnique, 41, 4, 485498 (1991)

13. A. Martinez, S. Palumbo, Proc. ASCE IFCEE 2018 Conf., Orlando, FL (2018)

14. B. Farhadi, A. Lashkari, Soils and Found., 57, 1, 111125 (2017)

15. A. Filippov, S. N. Gorb, Sci. Rep. 3, 1240 (2013)

16. U. Hiller, Zoomorphology, 62, 307-362 (1968)

17. S. N. Gorb, Attachment devices of insect cuticle. Dordrecht, The Netherlands: Kluwer Academic Publishers (2001) 
18. H. Marvi, D. L. Hu, J. of The Royal Soc. Int., 9, 76, 3067-3080 (2012)

19. J. Hazel, M. Stone, M. S. Grace, V. V. Tsukruk, J. of Biomech., 32, 5, 477-484 (1999)

20. W. Wu, C. Lutz, S. Mersch, R. Thelen, C. Greiner, G. Gomard, H. Hölscher, Beilstein J. of Nanotech., 9, 1, 2618-2627 (2018)

21. M. C. G. Klein, J. K. Deuschle, S. N. Gorb, J. of Comp. Phys. A, 196, 9, 659-668 (2010)

22. P. Manoonpong, D. Petersen, A. Kovalev, F. Wörgötter, S. N. Gorb, M. Spinner, L. Heepe, Sci. Rep. 6, (2016)

23. E. V. Gorb, S. N. Gorb, Beilstein J. of Nanotech., 2, 302-310 (2011)

24. R. Elbaum, L. Zaltzman, I. Burgert, P. Fratzl, Science, 316, 5826, 884-886 (2007)

25. H. T. Tramsen, S. N. Gorb, H. Zhang, J. of The Royal Soc. Interface, 15, 138, (2018)

26. H. H. Stutz, R. Doose, F. Wuttke, Open Science Interface Shear Device. in $\mathrm{W} \mathrm{Wu}$ and $\mathrm{HS} \mathrm{Yu}$ (eds), Proceedings of China-Europe Conference on Geotechnical Engineering. vol. 1, Springer, Springer Series in Geomechanics and Geoengineering, 1, 615618 (2018)

27. A. Martinez, H. H. Stutz, Géotechnique, in print (2018)

28. S. Palumbo, Anisotropic Interface Shear Behavior of Granular Soil and Surfaces Biologically-Inspired by Snakeskin. Master's thesis, The University of California Davis (2018)

29. A. Martinez, S. Palumbo, B. Todd, J. of Geotech. Geoenv. Eng. (under review, 2019) 